\title{
Establishing ties: You are responsible for your rose
}

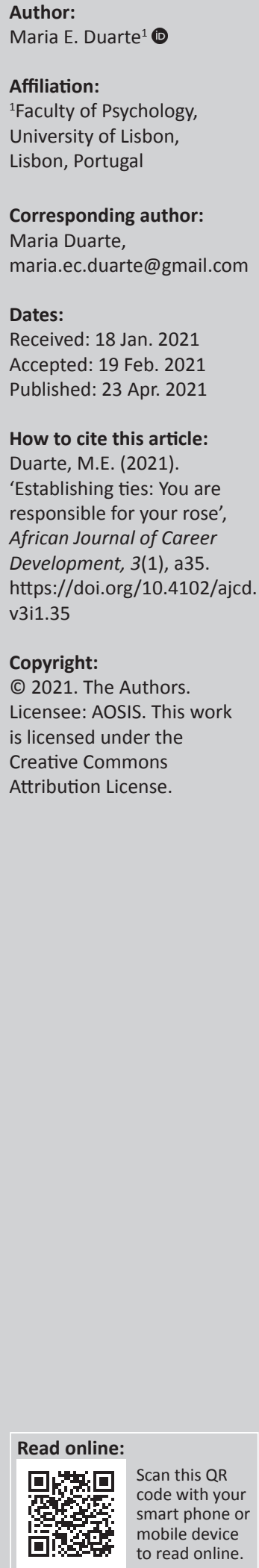

I have lived my life in the service of individuals, studying their stratums of meanings and forms and trying to teach the secrets of psychology to my students. I've learned that nothing in our relationships should be taken for granted, in particular, at this moment in history.

I've learned more from reading the classics and famous writers on the substance of human life than from hundreds of reports or scientific articles. I've learned about the limits of some illusions the futility of total accuracy, of absolute quantification, of complete knowledge. I believe that human experience is always more enriching compared to any interpretation.

Now, in this globalised world without political or ethical control that 'weakens' the foundations of our existence and gives rise to uncertainty, risk, lack of prospects and stability, and when actions to eliminate those same risks are diverted of the real sources of danger, it becomes easier to point out the reasons of uncertainties and risks that we face.

Therefore, some individuals need 'interpreters' who understand the utility of enlarging the small, accommodated or non-existed horizons, by making use of the potential of infinite dialogue with each one's condition.

Being useful to an individual, developing one's ability for entertaining different perceptions of the world and incorporating the other individual's perspectives on specific challenges may be viewed as an invitation to expand one's own perceptions. The main goal of counselling dialogue is to achieve coherence considering the individual's identity, self-concept and agency, and also to integrate events from the past and present and put them into the perspective of the future.

I present a different approach that is always under development, and which will probably never be complete: to develop a dialogue so that the counsellor and counselee develop a partnership where the counsellor must be aware of an obligation to support and participate in another individual's process, or in other words, create something together.

For that purpose, I refer to one of the most widely read books in the history of Western culture (Harari, 2015): the Little Prince (Mały Książę) by De Saint-Exupéry (1943). I will then highlight the dialogue between the Little Prince and the Fox (chapter XXI), which deals with the impossibility of a relationship between two creatures that are not known to each other, one that is in its own environment (the Fox), and another that comes from another world (the Little Prince):

Come and play with me, proposed the little prince. I am so unhappy. (p. 45)

I cannot play with you, the fox said. I am not tamed. (p. 45)

This impossibility of establishing a relationship is based on two main arguments: one is the absence of an affective tie or connection between them, and the other is simple: they do not belong to the same world (to the same planet):

Ah! Please excuse me, said the little prince. (p. 45)

But, after some thought, he added:

What does that mean 'tame'? (p. 45)

You do not live here, said the fox. (p. 45)

and, therefore, they do not have the same cultural allusions - whilst the Little Prince, in a strange world, was in search of people looking for identity ties, or something or someone to play with him 
(as usual in a human child), the fox fled from these same people because they used guns to hunt chickens (and, by inference, foxes), the fox, consequently, and in a sort of primary syllogism, wondered if that child, being human, would not also be as was implicit, in search of chickens, and of foxes to hunt:

What is it that you are looking for? (p. 45)

I am looking for men, said the little prince. What does that mean - 'tame'? (p. 46)

Men, said the fox. They have guns, and they hunt. It is very disturbing. They also raise chickens. These are their only interests. Are you looking for chickens? (p. 46)

But in his naivety, which contrasted with the knowledge of the world held by the fox characterised by the use of cunning, acquired by the experience of life, as a survival technique, the Little Prince guaranteed that what he was looking for was friends, thus not discriminating between people and animals.

It was only then, after the Little Prince used the word friends, that the Fox decided to answer the question persistently asked by the Prince, 'what does that mean - "tame"', as he did not know the concept of 'tame'. This was a point of argument used by the fox in order not to play with the Little Prince: the act of playing, assumed here to be a playful act, and also the act of two persons or two objects to articulate with each other to obtain a harmonious result, is possible only between people who are bound by some common ties and these ties, in a large comprehensive way are also affective - something that people tend to neglect:

No, said the little prince. I am looking for friends. What does that mean 'tame'? (p. 46)

It is an act too often neglected, said the fox. It means 'to establish ties'. (p. 46)

And the fox continues, these ties allow two people to become special each other whilst maintaining their own identity - the Fox will always be a fox, and the Little Prince will always be a human - because it is the only way they can be happy:

To establish ties? (p. 46)

Just that, said the fox. To me, you are still nothing more than a little boy who is just like a hundred thousand other little boys. And I have no need of you. And you, on your part, have no need of me. To you, I am nothing more than a fox like a hundred thousand other foxes. But if you tame me, then we shall need each other. To me, you will be unique in all the world. To you, I shall be unique in all the world ... (p. 46)

The fox further specifies referring to the distinctive features that allow the members of a group to identify with each other, but in opposition to another group whose elements are also united by distinctive traits - but different distinctive appearances:

I hunt chickens; men hunt me. All the chickens are just alike, and all the men are just alike. [...] But if you tame me, it will be as if the sun came to shine on my life. [...] And then look: you see the grain-fields down yonder? I do not eat bread. Wheat is of no use to me. The wheat fields have nothing to say to me. And that is sad. But you have hair that is the color of gold. Think how wonderful that will be when you have tamed me! The grain, which is also golden, will bring me back the thought of you. And I shall love to listen to the wind in the wheat ... (p. 46)

And it is also these ties that infuse in individuals a sense of responsibility for other individuals, especially those with whom they have established connections and who allow them to consider them as unique, similar to what we do since the very beginning of a counselling process:

Men have forgotten this truth, said the fox. But you must not forget it. You become responsible, forever, for what you have tamed. You are responsible for your rose ... (p. 48)

I am responsible for my rose, the little prince repeated, so that he would be sure to remember. (p. 48)

In brief, De Saint-Exupéry emphasises, through the voice of the fox, the importance of rituals in people's lives, insofar as they allow them to organise their lives so that each day may be different from the others, just as people should be in order to retain their identity:

Those also are actions too often neglected, said the fox. They are what make one day different from other days, one hour from other hours. There is a rite, for example, among my hunters. Every Thursday they dance with the village girls. So Thursday is a wonderful day for me! I can take a walk as far as the vineyards. But if the hunters danced at just any time, every day would be like every other day, and I should never have any vacation at all. (p. 47)

Let us recall and consider some of the basic ideas of these passages, all of them originate from the fact that the two creatures live in a dual reality: on the one hand, both interact with the same objective entities external to them (e.g. 'man', 'flower', 'the harvest'); but, on the other hand, these objective entities arouse in each of them subjective reactions resulting from their own experiences.

The first of these ideas is the impossibility of communication between 'individuals' because they do not belong to the same 'world' - I mean, the same environment - (You do not live here), and the lack of a connection between them (I cannot play with you. I am not tamed). The second idea is that the two 'individuals' have different cultural references: for the Little Prince, men are potential friends, whilst for the fox, men are fox and hen hunters.

The third idea to be retained is the importance of knowledge as held by the fox and the need to obtain it as embodied by the Little Prince who asks questions.

The fourth idea is clear: only the establishment of ties between individuals makes it possible to overcome problems and to co-construct relationships, which is represented here by reference to 'rituals' and by the construction of symbols: the yellow fields, which produce the bread that the Fox does not need, will remind of , in a situation of absence, the blond hair of the Prince. Finally, the fifth idea: the responsibility of the 
individual before the collective as a result of the establishment of ties: 'You become responsible, forever, for what you have tamed. You are responsible for your rose ...'

In a technical language: to create something together where meanings are co-created during the conversation, where new dialogues gradually take shape, contain a deeper meaning and rest on a value-based conviction, creating, in that way, a degree of sustainability, trying to connect phenomenology and social constructionism, by placing the concept of meaning at the 'core business' of conversation or dialogues.

We all read The Little Prince - after all, it is the fourth most well-read book, excluding religious and doctrinal texts, after Don Quixote of La Mancha (1605) by Miguel de Cervantes, A Tale of Two Cities (1859) by Charles Dickens and The Lord of the Rings (1954-1955) by R.R. Tolkien (Harari, 2015) - and read it in the category of literature relevant for children and young people, an age group to which tradition almost exclusively attributes the right to imagination and fantasy. Indeed, a child that travels freely from planet to planet, each inhabited by a single being endowed with consciousness and the ability to express in a language, amongst them were plants and animals that speak and think like humans (though maintaining the idiosyncrasies of their own species), cannot be possible anywhere else than in a story for children. And yet...

From the point of view of objectivity, the 'worlds' through which the Little Prince travels, as well as the 'characters' with which he interacts in each of these worlds (the narrator, the flower, the king, the conceited man, the tippler, the businessman, the lamplighter, the old geographer, the snake, the echo, the roses, the fox, the railway switchman, the merchant and of course the lost aviator ...) belong to the universe of fable and fantasy - that, by definition, absurd manifestations are treated and understood as normal behaviours.

However, in this journey through the little isolated worlds, each of the characters (which, in the case of humans, are defined by their occupations) contributes to the knowledge of the Little Prince creating a 'truth' from which he can see the world. And this truth is not the world that exists, the real world, but the way each character (both the Little Prince and the interlocutors) understands and assimilates it.

Given this duality, the reader 'forgets' the unlikely of the successive scenes (not even wondering how the Prince can travel between asteroids, or if there are life and characters identical to the human ones of the Earth), and concentrates on the essential, which is the experience of each one of the characters (inanimate, animated or human, but always referred to the real world - the railway switchman, the sheep that eat little bushes, the fox that does not like hunters) voiced by themselves, helping the child to grow by transmitting the truths that really matter. We could find here echoes of Husserl's phenomenology (1907) and his ideas about communication.
Dialogue defined as an act of communication. For Husserl, interpreted by Płotka (2009), University of Cardinal Stefan Wyszyński in Warsaw:

[C]ommunication motivates others to do something. [...] there is no doubt, the communication introduces completely new dimension of human practice. Namely, according to communicative acts, I am never alone, and my actions should be grounded on the responsibility for the other. Sketched relation is two-sided, but the aim is common: a consensus. (p. 90)

Therefore, there can be no rigid or standardised models of dialogue, regardless of the situation in which it occurs: in an interview situation, which presupposes a dialogue, the interviewer - who is an integral part of the process and not an external agent interested in obtaining from the respondent a given answer that can be conditioned - is not alone, that is, he has to take into account the view that the other has of the world, and respect it.

This is the case with the model proposed by Savickas (2015) which fits into this phenomenological concern of Husserl, in that it is organised around items that aim not to condition the respondent's response but to motivate him or her to act - in this case, telling his life story, which will be one of the possible representations of his own unique way of seeing the world and from which, from then on, he will also become a part. By telling the stories, the individual can connect his or her subjective realities to the challenges of social world. As Bruner (2002) and Gergen and Gergen (2006) pointed out, subjective perceptions and resulting personal self-constructs need to be replaced or modified in social discourses that are relived in the counselling dialogue.

Another selection could be that which can be described as affections. Identity simply does not exist without the language of affection, from which inter-personal relationships and people's relationships with the context in which they find themselves or could find themselves are constructed and developed. The language of affection, which theoretically can be disassociated from other forms of language, for example, cognition in the sense of the selection, storage and treatment of information, implying a choice of object or situation (the object of our affections is never an aleatory choice), can be observed through the manifestation of an individual's feelings in relation to an object or situation. Put another way, this is a manifestation of the emotions which being the individual's intense affective responses to the stimuli of their surroundings, can also influence the process of choosing new objects and situations that will in turn require new responses.

The concept of dialogue, in being complemented by interindividuality, is a fundamental aspect when it comes to the positioning of that which forms the heart of counselling (Duarte, 2017). The notion of dialogue becomes theoretically central to the understanding of the various situations that bring something to that which we refer to as life.

Dialogue implies integrating thoughts into an act of communication: in opposition to the foundationalism view of 
language, it is the adoption of the hermeneutic or dialogical positions, as reflected in the works of Gadamer (1975) and Bakhtin (1981) respectively. Hermeneutics is concerned with understanding the meaning that people make of their lives. It takes into consideration the historical and psychological reality of the lived experience of the person whose life is being interpreted, and that of the interpreter herself/himself, because 'an interpreter understands by constant reference to her own perspective, preconceptions, biases, and assumptions that rest, fundamentally, on her lifestyle, life experiences, culture, and tradition' (Tappan, 1997, p. 649). From the hermeneutic perspective, we understand the new in terms of what we already know, and more importantly, in terms of who we are.

Similarly, Bakhtin (1981) has emphasised the dialogical nature of all understanding. Understanding pre-supposes (and recognises) the other, with whom one can agree or disagree. Bakhtin (1981) argues that:

The consciousness of other people cannot be perceived, analyzed, as objects or as things - one can only relate to them dialogically. To think about them means to talk with them; otherwise they immediately turn to us their objectivized side: they fall silent, close up, and congeal into finished, objectified images. (p. 68)

Contrary to idealistic philosophy, dialogism argues that a fully voiced consciousness (i.e. with its own ideas and points of view) is to be found at the point of contact with another equally-voiced consciousness. This implies that dialogues need to genuinely engage with the context.

\section{Conclusion}

Are we capable to close the gate and escape from a technocratic perspective of knowledge, and take new roads, which means, pay attention to the new emerging perspectives other than the traditional way to face individual or collective problems and, also, highlight the importance of individual differences as opposed to standardisation, which led us, during the machine age of the 20th century to the mechanisation of behaviours as if all individuals were copies of a lost original ...?

The reality of globalisation and the concurrent worldwide competitiveness impose a shift on intercultural research towards an integrative background to both common and regional competencies to achieve added value and usefulness of research. It also involves evaluation and its meaning of concerns related with conceptual definitions and the context of its operationalisation, which means the identification of the relevant contents of culture knowledge is also crucial.

Nowadays, intervention is not a cumulative process of the interpretation of the assessment data: it integrates environmental variables, and also considers the cultural context.

Regarding the consequences of globalisation, it seems to me that it is important to recognise the desirability of a greater proximity to culture in those issues.
Guidance and counselling for solidarity, social justice and dialogues in a diverse world are the motto of the conference. I believe it would be possible to put together - United Nations Eduactional, Scientific and Cultural Organization (UNESCO) Chair on Lifelong Guidance and Counselling and its University Twinning and Networking Programme (UNITWIN) partners a narrative collaborative practice, and, in that way, 'taking part' in the history of the other and with it being supportive, following the dialogue in which ties were established, so well synthetised in the sentence 'You become responsible, forever, for what you have tamed. You are responsible for your rose ...'

\section{Acknowledgements}

This article is partially based on the author's keynote address (Duarte, 2018) at the International Conference: Counselling for solidarity, social justice and dialogues in a diverse world, 24-25 May 2018.

The author would like to thank the editor of African Journal of Career Development, Prof. Kobus Maree.

\section{Competing interests}

The author declares that she has no financial or personal relationship that may have inappropriately influenced her in writing this article.

\section{Author's contribution}

M.E.D. declares that she is the sole author of this research article.

\section{Ethical considerations}

This article followed all ethical standards for carrying out research without direct contact with human or animal subjects.

\section{Funding information}

This research received no specific grant from any funding agency in the public, commercial, or not-for-profit sectors.

\section{Data availability}

The author confirms that the data supporting the findings of this study are available within the article.

\section{Disclaimer}

The views and opinions expressed in this article are those of the author and do not necessarily reflect the official policy or position of any affiliated agency of the author.

\section{References}

Bakhtin, M.M. (1981). The dialogic imagination. Austin, TX: University of Texas Press. Bruner, J. (2002). Making stories - Law, literature, life. Cambridge, MA: Harvard University Press.

De Saint-Exupéry, A. (1943). Le Petit Prince. English translation: The little prince. New York, NY: Reynal and Hitchcock.

Duarte, M.E. (2017). Counseling and well-being: on the road to realities. British Journal of Guidance and Counselling, 45(5), 508-519. https://doi.org/10.1080/03 069885.2017.1309641 
Duarte, M.E. (2018). Establishing ties: You are responsible for your rose. In International Conference: Counselling for solidarity, social justice and dialogues in a diverse world, 24-25 May 2018. (Keynote address). The United Nations Educational, Scientific and Cultural Organization.

Gadamer, H-G. (1975). Truth and method. New York, NY: Continuum.

Gergen, M.M., \& Gergen, K.J. (2006). Narratives in action. Narrative Inquiry, 16(1), 112-121. https://doi.org/10.1075/ni.16.1.15ger

Harari, Y.N. (2015). Homo Deus. A brief history of tomorrow. London: Vintage, Penguin Books, 2017.
Husserl, E. (1907). The idea of phenomology. Dordrecht: Kluwer Academic Publishers, 1999.

Płotka, W. (2009). Between language and communication: A Husserlian approach. Lingua ac Communitas, 19, 85-93. Retrieved from https://www.academia. edu/1415449/Between_Language and_Communication_A_Husserlian_Approach

Savickas, M.L. (2015). Life-design counseling manual. Retrieved from www.vocopher.com Tappan, M.B. (1997). Interpretive psychology: Stories, circles, and understanding lived experience. Journal of Social Issues, 53(4), 645-656. https://doi. org/10.1111/j.1540-4560.1997.tb02453.x 